\title{
A method for the improvement need definition of large, single-track rail network analysis and infrastructure using "Rail Traffic System Analysis"
}

\author{
T. Kosonen \\ Head of Railway Project Planning Unit, \\ Finnish Transport Agency, Finland
}

\begin{abstract}
A major change in Finnish rail freight transport flows caused a need to have a thorough capacity analysis of the network and a need to estimate how infrastructure should be improved to match the future traffic situation. For this purpose a new method was developed. Its main goals were to have an approach that combines different levels of traffic planning, is suitable for single track lines, takes into account the commercial aspects of the traffic and takes into account the network related dependencies. A large study was successfully done with the method and it showed that it could match its goals. Therefore, it was taken into regular use and it is integrated into the long term planning process of the Finnish rail network.
\end{abstract}

Keywords: capacity, calculation, cost/benefit, single track, planning, network.

\section{Introduction}

The total length of the rail network in Finland is about $5900 \mathrm{~km}$, of which about $90 \%$ is single track. Almost all of the track sections are mixed traffic, only a few sections are dedicated to passenger or freight traffic only. The annual amount of passenger trips is about 67 Mio and the total amount of annual freight is about 45 Mio tonnes. About $25 \%$ of all freight traffic is Russian-related.

Recent changes in Finnish forest sector strategies and wood export customs decisions made by the Russian government had created a need for significant change in the Finnish freight transport system. Major traffic flows had to be 
turned around. Traditionally, the wood needed in eastern Finland's large paper mills has been imported from Russia. Now it has to be transported from western and northern Finland. This caused major changes to the use of the network.

To evaluate the impacts of this change and to define the improvements needed for it, a large transport study was started by Finnish Rail Administration in 2008 [1]. The method used in this study was developed during this project and it is called "Rail Traffic System Analysis". Background work for method development was done in earlier studies that took place in 2005-2007 and handled similar kinds of issues on a smaller scale $[2,3]$.

\section{Concept of "Rail Traffic System Analysis"}

Traditional capacity analysis methods (for example UIC 406) are usually based on the idea of theoretical capacity and its utilization [4]. Usually, analysis based on the calculation of the percentage of theoretical capacity and how much is still available for additional traffic is currently used. This can be done by compression of timetables or other similar methods.

These methods are very simplified and handle only one line section at a time. Adjacent sections are handled separately and optimized independently. This is why these methods are not able to handle network level studies in an accurate way. These methods also do not take into account the commercial aspects that are always present in railway traffic. Every train has to have certain commercial interest or else it makes no sense to operate the train at all.

System analysis is a method that answers the question of capacity and its availability, but at the same time is able to handle network level studies and commercial aspects.

It consists of four or five different steps as follows:

Step 1: Traffic flow estimation

Step 2: Train amount calculation

Step 3: Timetable definition and planning

Step 4: Traffic quality analysis

Step 5: (Cost/benefit analysis)

\section{Macro level studies}

System analysis starts from a high level in step 1. At this stage general economic forecasts, land use plans and railway transport customers' interviews are used to form different scenarios of future traffic flows. This can be done both for passengers and for freight. The result of this step is traffic flow estimations for passengers and different goods types in the observation area.

In step 2 traffic flow estimates are transformed into daily traffic amounts. This is done for freight by dividing tonnage flows with average train weights and operation days per year. In passenger traffic, the same thing is done for dividing passenger flows by average carrying capacity for different train types. Seasonal peaks are taken into account so that the maximum traffic needs on the network can be illustrated. The result of step 2 is daily future train amounts in the observed track network in different scenarios. 


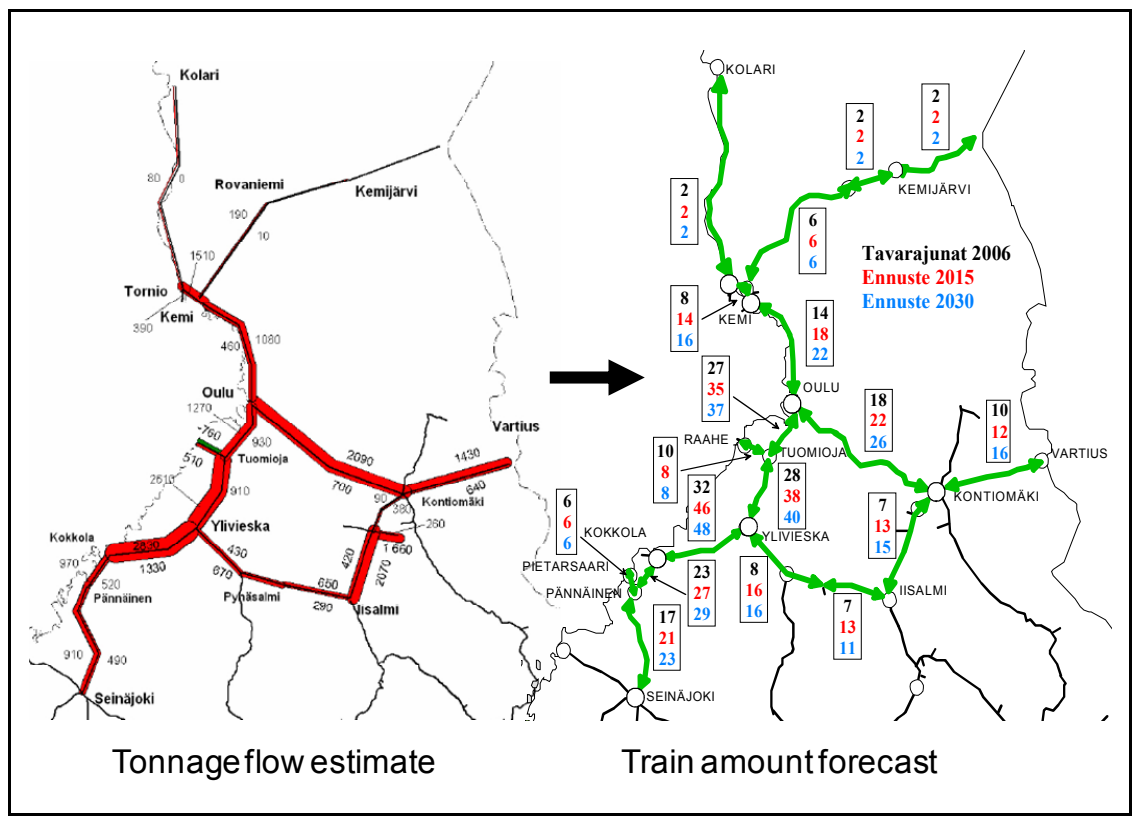

Figure 1: From goods flow to train amounts.

\section{Detailed planning and analysis}

Step 3 consists of the definition of commercial boundary conditions for future trains and is based on future timetable planning for the observed network. Commercial boundary conditions are typically time slots in which the train has to leave its origin and/or in which it has to arrive at its destination station. In Finland this step is done in co-operation with operators or transport customers in freight traffic. In passenger traffic, usually the regular interval timetable is used so a separate boundary condition definition is not usually done.

Traffic planning is done in a capacity allocation priority order that is presented in the network statement. In Finland the order is the following:

- Synergic passenger traffic entity

- Express passenger trains

- Transport for processing industry

- Local and other passenger traffic

- Other regular freight traffic

- Freight traffic not requiring strict transport times

- Other traffic

In practise this leads to the situation where the passenger traffic regular interval timetable is planned independently, first and freight trains are added on top of it. If available capacity does not allow train timetable planning according to the defined commercial boundary conditions, this is marked down as a serious 


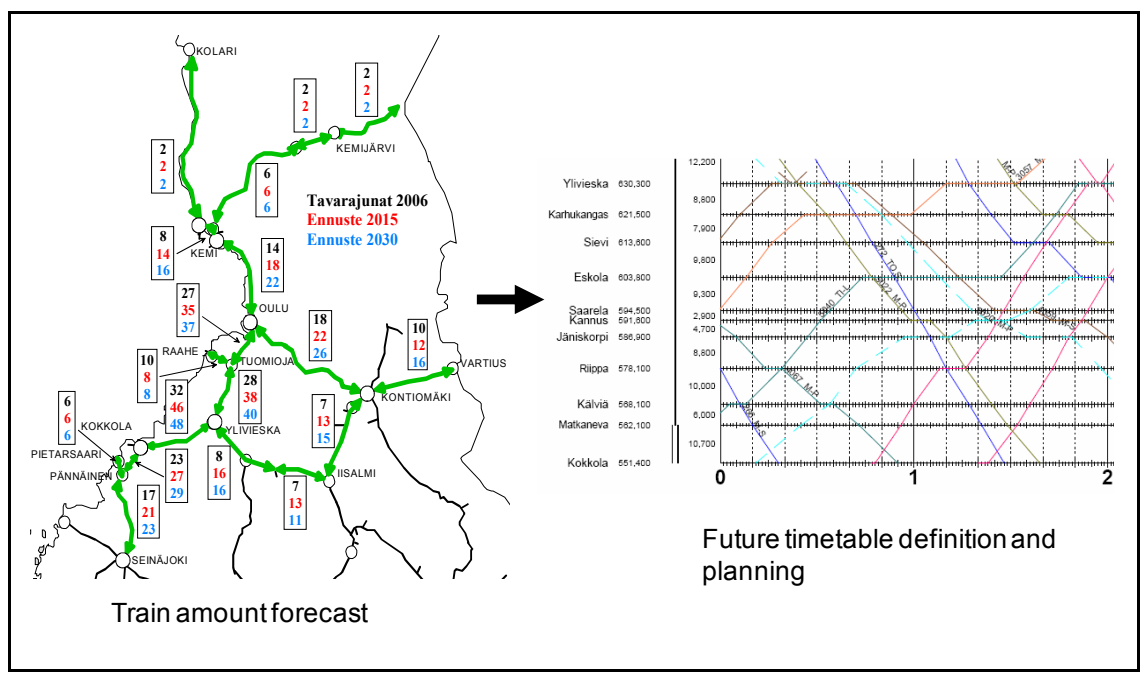

Figure 2: $\quad$ From train amounts to train paths.

signal of insufficient capacity. Traffic planning is done with simply usable planning software (usually Swiss Viriato). The result of step 3 is planned timetables for estimated future traffic in different scenarios.

The future traffic quality on different scenarios is analyzed in step 4 . This is done by collecting a large amount of train run describing data from the timetables planned in the earlier step. For this process a macro that produces these figures automatically from the timetable database is used.

The key figures observed are the following:

- Absolute train running time on a defined section

- Average running times of all the trains on a defined section

- Deviation of train running times on a defined section

- Average speed of a train on a defined section

- Average speed of all the trains on a defined section

- Deviation of train average speed times on a defined section

- Absolute non-commercial stop time of a train on a defined section

- Average stop times of all trains on a defined section

- Total non-commercial stop times of all the trains on a section (daily, weekly and yearly)

The data from different sections is compared with each other in order to locate the problematic areas of the network. If a large network is observed, usually a map illustration of the figures is necessary to be able to form an accurate picture of the traffic quality. This can be done with GIS systems.

The situation of capacity usage on a single line section can be observed, for example, from the deviation of the running times of a train group. If there is a lot of free capacities, all the trains with similar properties get approximately similar train paths, have almost the same running time and the deviation is small. 
If there are certain problems with capacity, the deviations in the running time are larger as the trains that are planned first get the smoothest train paths and the rest have to manage with the worse paths that are left. The bigger the deviation is, the worse the capacity situation is.

The problem is the situation where the capacity is in full use. In that case no additional trains can be added to the timetable. It means that their running behaviour figures will not be taken into account, as they do not exist. These situations must be handled separately.

If the traffic quality is too low on certain parts of the network, it is possible at this stage to observe the impacts of different infrastructure improvement actions to the traffic system. This can be done by changing the infrastructure properties and repeating steps 3 and 4 again. This iterative process can be repeated until an adequate level is reached. The result of step 4 is a representation of the capacity and traffic quality situation in different future traffic scenarios. An additional result can also be a list of required infrastructure improvement actions to reach a tolerable traffic quality level in the future.

During steps 3 and 4 the relations between different infrastructure improvements can be pointed out. Usually some improvements are beneficial only if some other improvements are done first. It is very important to notice these relations on a network level so that the infrastructure upgrade actions can be prioritized.

\section{Economical aspects}

Step 5 is used if there is a need for cost/benefit analysis of the infrastructure improvement actions. The main figures produced in step 4 are usable for calculating operating costs for different traffic models. In Finland we have used an operating cost model that was originally created by Swedish Banverket [5].

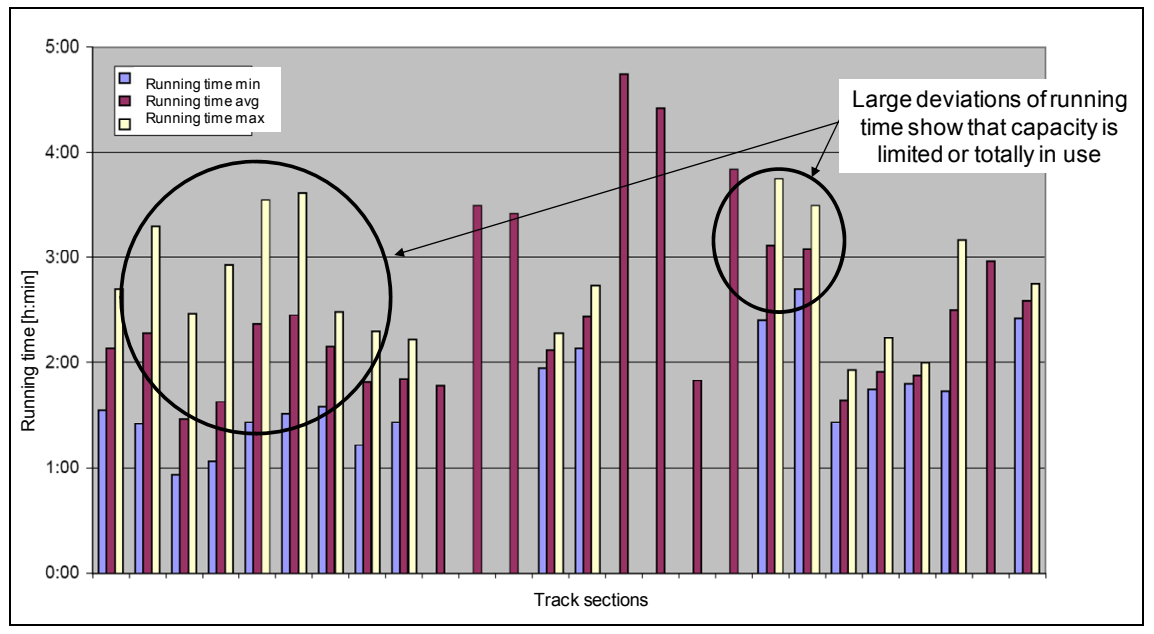

Figure 3: Example of running time deviations. 


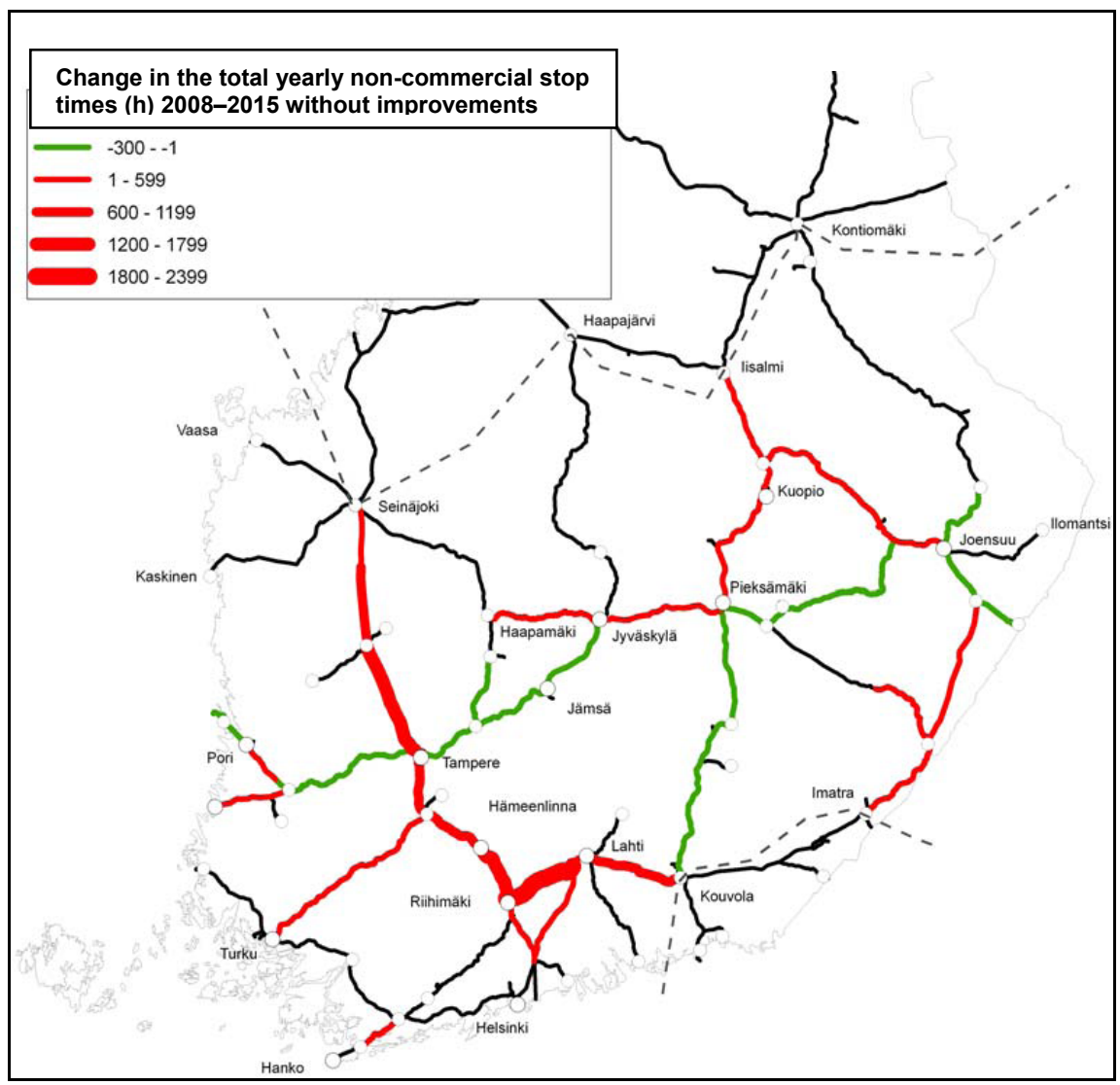

Figure 4: Example of a non-commercial stop time change on a network level.

It is based on the basic parameters, such as train composition and travel time of a train. It has preset values for the cost of the rolling stock, personnel, emission values, etc. With this, the operation cost for a certain timetable structure can be calculated and different alternatives can be compared with each other. A macro that calculates operation cost figures straight from the timetable database is currently under development.

With the operation cost difference in the studied alternatives and the infrastructure improvement cost needed to achieve it, the cost/benefit ratio can be calculated.

\section{Conclusion}

The "Rail Traffic System Analysis" method has proven to be a usable and most credible tool for capacity analysis in the Finnish network. Its best features are the possibility to take commercial aspects of the rail traffic into account and the 
possibility to provide illustrative and reliable results of railway capacity in such a complex environment as a single track network.

It combines different approaches of rail traffic planning together, starting from macro level studies with traffic flows and ending in detailed planning of single train operations. This makes it possible to have a thorough understanding of the real needs of the rail system in the future and how they can be achieved.

The following results have been produced for the Finnish network:

- Future traffic amounts on the network

- Future capacity bottlenecks of the network

- Comparison of the effectiveness of different future traffic models and routing alternatives

- Infrastructure improvement needs of the network

- Prioritization of infrastructure improvement action

- Cost/benefit ratio for infrastructure improvement actions

With this method the complex case of major freight traffic flow change on the Finnish network could be handled and a three phase program for rail infrastructure upgrade to years 2010-2025 formed. It has been decided that this method will be used regularly in the future to check the relevance of the upgrade program and to adjust it in the direction that is most beneficial.

\section{References}

[1] Iikkanen, P., Kosonen, T., Mukula, M., Kiuru, T., A 16/2009 Etelä-Suomen rataverkon tavaraliikenteen kehittäminen, Finnish Rail Administration, Traffic system unit, Helsinki 2009 (in Finnish).

[2] Iikkanen, P., Kosonen, T., Rautio, J., A 4/2005 Kaakkois-Suomen rataverkon tavaraliikenteen kehittäminen, Finnish Rail Administration, Traffic system unit, Helsinki 2005 (in Finnish).

[3] Iikkanen, P., Kosonen, T., Rautio, J., Mähönen, N., A 5/2007 PohjoisSuomen rataverkon tavaraliikenteen kehittäminen, Finnish Rail Administration, Traffic system unit, Helsinki 2007 (in Finnish).

[4] UIC leaflet 406, Capacity, UIC International Union of Railways, France 2004.

[5] Banverket guidance for calculation - Appliance for socio-economic calculations in the railway sector, BVH 706, Sweden 2007 (in Swedish). 